\title{
O valor da democracia na literatura infantil'
}

\section{The Value of Democracy in Children's Literature}

\author{
ÂNGELA BALÇA \\ Universidad de Évora - CIEC \\ Portugal \\ FERNANDO AZEVEDO \\ Universidad do Minho - CIEC \\ Portugal \\ MOISÉS SELFA SASTRE \\ Universidad de Lleida \\ España \\ apb@uevora.pt \\ fraga@ie.uminho.pt \\ mselfa@didesp.udl.cat
}

(Recibido: IO-OI-2OI8; aceptado: o6-o6-2018)

Resumo. Numa Europa, que também se questiona a si própria politicamente, várias têm sido as vozes que levantam o espectro do declínio das democracias e do emergir de tentações totalitárias. A literatura infantil não é ideologicamente neutra e encerra certamente, mediante a modelização dos realia, uma série de mundos possíveis, onde se questiona a prática e se sugerem vias alternativas para a construção coletiva de uma sociedade politicamente mais comprometida com os valores mais caros à Humanidade. Neste estudo, pretendemos discutir textos paradigmáticos da literatura infantil portuguesa, nomeadamente de um de autor comprometido ativamente desde sempre com a democracia, com a liberdade, com a cidadania, como António Torrado. Na obra de António Torrado, através do humor e da fina ironia, transmitem-se mensagens e valores, dando-nos uma visão das suas crenças políticas.

Palavras-chave: literatura Infantil; democracia; liberdade; cidadania; valores.
Abstract. TIn a Europe that questions itself politically, many have raised their voices on the spectre of the decline of democracies and the emergence of totalitarian temptations. Children's literature is not ideologically neutral and certainly, through the modelling of realia, contains a series of possible worlds where alternatives are practiced and questioned that collectively construct a politically committed society, containing the values most appreciated by Humanity. In this study, we intend to discuss paradigmatic texts of Portuguese children's literature, namely by an author actively committed to democracy, freedom and citizenship; António Torrado. In the works of António Torrado, through humour and sharp irony, messages and values are transmitted, giving us a view into their political beliefs.

Keywords: children literature; democracy; freedom; citizenship; values.

\footnotetext{
${ }^{\text {I }}$ Para citar este artículo: Balça, Ângela, Azevedo, Fernando y Selfa Sastre, Moisés (20I8). O valor de democracia na literatura infantil. Alabe 18. [www.revistaalabe.com]

DOI: I0.15645/Alabe20I8.18.6
} 


\section{Introdução ${ }^{2}$}

Os textos literários mantêm relações mediatas com o mundo empírico e histórico factual em que se situam os seus leitores. Tal significa que, obedecendo ao protocolo da ficcionalidade, os seus mundos possíveis relatados não podem ser lidos como uma cópia ou espelho desse mundo, mas possibilitam interrogar esse mundo, originando a consecução de importantes efeitos perlocutivos.

A literatura infantil, pela sua relação com propósitos formativos, tem desde sempre privilegiado a apresentação de determinados modelos do mundo que se possam configurar como relevantes para os mais jovens, ajudando-os a construir e a adquirir valores tidos como positivos e pertinentes no âmbito das respetivas comunidades interpretativas.

Como assinala Reynolds (2007:2),

Childhood is certainly a time for learning to negotiate and find a place in society, but it is also about developing individual potential suited to a future in which societies could be different in some significant ways (...). It is not accidental that at decisive moments in social history children have been at the centre of ideological activity or that writing for children has been put into the service of those who are trying to disseminate new world views, values, and social models.

No mundo da literatura infantil portuguesa, esses propósitos formativos surgem, por vezes, associados a textos literários de grande beleza, muitos deles extraordinária e aparentemente simples. Com o país dominado por uma ditadura com cerca de quatro décadas, em meados do século XX, muitos autores, que ainda hoje escrevem obras de literatura infantil, começaram a escrever antes da Revolução de 25 de abril de 1974. Foi através desses textos que, subtilmente, os autores iniciaram as crianças nos valores que lhes eram caros na construção de uma sociedade diferente - a liberdade, a cidadania, a democracia. Com a Revolução dos Cravos e com a entrada de Portugal para a União Europeia, a necessidade de escrever estes textos manteve-se. Editados e reeditados até hoje, a eles se juntam textos de temáticas mais concretas, por vezes históricas, mas cujo fim é exatamente o mesmo - levar as jovens gerações ao questionamento sobre a sociedade que os rodeia, sobre a sua participação cívica nessa mesma sociedade, sobre o direito e o dever de pensar, de agir de modo livre e democrático. Como explicitou Hollindale (I988: 23) "a large part of any books is written not by its author but by the world its author lives in."

\footnotetext{
${ }^{2}$ Este estudo teve o financiamento do CIEC (Centro de Investigacão em Estudos da Crianca), pelo Projeto Estratégico UID/CED/oo3I7/20I3, através dos Fundos Nacionais da FCT (Fundação para a Ciência e a Tecnologia), cofinanciado pelo Fundo Europeu de Desenvolvimento Regional (FEDER) através do COMPETE 2O2O - Programa Operacional Competitividade e Internacionalização (POCI) com a referência POCI-OI-OI45-FEDER-OO 6562.
} 
Os textos de literatura infantil que interrogam o mundo e se centram sobre os pilares que constituem, hoje, as sociedades democráticas europeias têm novos desafios a enfrentar. Consideramo-los fundamentais na mensagem que partilham com as crianças e os jovens, numa Europa com múltiplos desafios, desde a crise económica e financeira ao problema da imigração; numa Europa que, de forma contundente, fala a duas vozes, a do norte e a do sul; numa Europa que vê crescer nacionalismos algo exacerbados, que julgávamos bem enterrados há muito.

A Europa tem-se igualmente questionado sob o ponto de vista político e são várias as vozes que têm assinalado o declínio do conceito de democracia e a emergência de tentações totalitárias. Professores, intelectuais e filósofos como George Steiner (2OII) não hesitam em expressar o sentimento, experimentado pelos povos da nossa contemporaneidade, segundo o qual "A política tornou-se o refúgio dos medíocres" (Steiner, 2OII: 47). Este intelectual também partilha a angústia sentida nos nossos tempos - "Parece-me que, hoje, o nosso maior crime é o de não deixarmos muita esperança aos jovens. Que lhes deixamos neste momento como visão, como perspectiva de futuro?” (Steiner, 2OII: 46).

A literatura infantil, pela modelização dos realia, apresenta determinados mundos possíveis, interrogando práticas e sugerindo modos alternativos de ver, olhar e pensar, buscando criar uma sociedade politicamente comprometida com valores autenticamente humanos.

Neste artigo, analisaremos alguns textos literários para crianças, que consideramos paradigmáticos, de um autor português ativamente comprometido com valores como a democracia, a liberdade e a cidadania, como é António Torrado. Na sua obra, aspetos como o humor e a ironia subtil partilham, com o leitor, mensagens e valores, dando-lhe preciosas informações acerca das suas crenças ideológicas e cívicas. Assim, a obra de António Torrado parece ser representativa de uma autêntica "Política da Advocacia" (Sutherland, I985: I45), suscitando, nos seus leitores, um número significativo de determinados efeitos perlocutórios.

\section{Desenvolvimento}

António Torrado, nascido em I939, começou a escrever ainda muito antes da Revolução de 25 de abril de 1974 . Após a Revolução, a sua obra consolidou-se, bem como a sua ação, pedagógica e cívica, presente não só nos seus textos literários para os mais novos, mas também na sua escrita de intervenção para adultos, alargando-se mesmo às novas tecnologias. António Torrado foi o autor de uma das páginas web mais consultadas pelos alunos e professores portugueses até há poucos anos, a página da História do Dia.

Dono de um fino humor e de uma cortante ironia, muitos dos seus textos literários de potencial receção infantil e juvenil deixam transparecer o seu pensamento político, através de personagens ou situações insólitas. Pimenta (2OIO) socorre-se das palavras de Leonor Riscado, afirmando esta última que "O olhar de António Torrado sobre as 
pequenas e grandes coisas, as pessoas, o mundo, afinado pelo registo da ironia, do humor ou da ternura abre o apetite dos leitores" (Pimenta, 2OIO: s/p), para a excelência da obra deste escritor.

António Torrado escreve com mestria o conto curto, tendo afirmado mesmo, como menciona Pimenta (2OIO: s/p), "É o meu modelo de escrita: insinuar mais do que dizer; sugerir mais do que declarar.” Modelo de escrita que deixa espaço aos seus leitores mais novos para pensar, refletir, sonhar. O escritor afirmou "Os meus livros já foram lidos por várias gerações” (Pimenta, 2OIO: s/p), tendo a consciência de quanto a sua obra literária para crianças contribuiu para o desenvolvimento da literatura infantil em Portugal e para a formação de sucessivas gerações de leitores: "Agora, parece que o patriarca sou eu (...). Já fiz tudo, já encantei gente. Tenho razões para me sentir feliz e realizado (...).” (Pimenta, 2OIO: s/p)

Neste estudo, iremos debruçar-nos sobre quatro textos de António Torrado: "O gato que era rei”, incluído no álbum Ojardim zoológico em casa (ı975); O Trono do Rei Escamiro (1977); "O elefante do rei" e "O rei das pernas tortas", inseridos estes dois últimos na coletânea Dez Contos de Reis (I990). A democracia, como valor supremo, está sempre presente nos seus textos, associada ao valor da liberdade e da cidadania.

Mas antes de nos debruçarmos sobre aqueles quatro textos, não podemos deixar de refletir, ainda que sucintamente, sobre uma das obras-primas de António Torrado - $O$ veado florido - objeto de um estudo mais detalhado em Balça, Azevedo e Selfa (2OI7). $O$ veado florido foi editado pela primeira vez em I972, portanto ainda antes da Revolução de I974, pela Editorial O Século; posteriormente esta obra foi reeditada em I999, pela Livraria Civilização e a sua última edição é de 20I5, pela Editora Asa. Leonor Praça, Manuela Bacelar e Cristina Valadas foram as ilustradoras das respetivas edições desta obra.

Este álbum narrativo, que é hoje um texto basilar na obra de António Torrado, constitui um grito a favor da liberdade e uma condenação da opressão, da tirania, em última instância, da ditadura. O álbum encerra em si uma metáfora: todos necessitam de liberdade para poderem viver; caso se vejam privados dela, indubitavelmente estão condenados a morrer. A obra contém uma história simples, composta por três personagens: um homem muito abastado, o seu criado e o veado florido. Para além da explícita estrutura de poder, aqui dada a ler pela presença do "senhor muito rico", o álbum assinala que este senhor gostava de exibir a sua riqueza, representada por "uma colecção singular de animais nunca vistos" (Torrado,I972: s/p), encerrados em jaulas doiradas, prontos a serem apreciados pelos amigos e visitas deste homem. Os animais singulares, porquanto possuidores de traços do domínio do onírico, eram muito bem tratados, e ainda que vivessem em "jaulas doiradas", a privação da sua liberdade fazia com que rapidamente morressem. Neste lote surgiu, a certa altura, um animal único e singular: um veado com hastes floridas! Porém, a prisão, a falta de liberdade despoletam no veado um caminho que levará inexoravelmente à sua morte. Como todos os déspotas e os seus fiéis seguidores, o "senhor muito rico" e o criado não conseguiram ver os sinais enviados por aqueles que sofriam a sua opressão. Os animais singulares desapareceram da face da Terra e, nas 
jaulas doiradas, acabaram por morrer todos os bichos, numa metáfora aos efeitos devastadores, numa sociedade, de um governo liderado por um ditador, caracterizado por norma pela falta de liberdade, pelas perseguições e pelas prisões daqueles que são diferentes e que pensam de outro modo.

Em seguida, entraremos então na análise dos quatros textos de António Torrado, referidos anteriormente.

O primeiro texto intitula-se "O gato que era rei" e está inserido na coletânea $O$ jardim zoológico em casa, publicada pela Plátano Editora, em I975, com ilustrações de Eduardo Perestrelo. Nos anos seguintes, esta obra conhece várias reedições $\left(3 \cdot{ }^{a}\right.$ edição em r980) e atualmente vários dos seus contos integram outras coletâneas do escritor, que dão resposta a um mercado editorial de grande sucesso, em redor de António Torrado e da sua obra.

"O gato que era rei” é um pequeno conto, com duas partes distintas, que se encadeiam (Todorov, I97I), estando bem assinaladas estas duas partes no próprio texto, com as seguintes frases: "AINDA NÃO É A HISTÓRIA, MAS FALTA POUCO”, "AGORA É QUEA HISTÓRIA VAI COMEÇAR” (Torrado, I975: 3I, 35). Comum a estas duas partes encadeadas do conto é o gato Xanana. Se na primeira parte da história, o narrador relata uma conversa escutada na sala de espera de um consultório veterinário, na segunda parte o narrador confessa: "para me entreter, pus-me a imaginar a história de um gato transformado em rei...” (Torrado, I975: 34). E aqui começa a parte do conto onde a crítica ao poder, às instituições, à falta de democracia marcam presença viva, através do humor, da ironia e do nonsense.

O gato Xanana vivia no palácio real e pertencia ao rei. Era um gato feliz, protegido, bem tratado e respeitado por todos, "embaixadores e generais, duques e marquesas, condes e viscondes" (Torrado, I975: 35). Como o rei gostava muito do gato Xanana, ele assistia no colo do monarca aos desfiles,

Quando, diante do dossel real, os exércitos de mosqueteiros, lanceiros e soldados, ao som de trombetas e ao ritmo dos tambores, passavam em continência, nem se chegava ao certo a saber a qual dos dois, se ao rei, se ao gato, eram dirigidas as homenagens. Ele próprio, o Xanana, não tinha a certeza. (Torrado, 1975: 35)

Na verdade, assistimos aqui a uma crítica bem-humorada ao poder absoluto deste rei e, por extensão, a todos os poderes autocráticos. Por princípio, a elite de um estado, supostamente o conjunto da população mais bem preparado e mais bem-educado, seria seguramente uma das vozes críticas e ativas desse estado; neste caso, como em tantas ditaduras por esse mundo fora, a elite é amorfa, obediente, submissa, a ponto de não distinguir entre o rei e o seu gato. 
A população, o povo, acaba por ser vítima destes poderes despóticos. Num dia em que o rei, como gato Xanana, recebia em audiência os homens do povo, por algum tempo o monarca ausentou-se da sala do trono. Os homens do povo esperavam, para serem recebidos pelo rei, "dispostos em bicha numa das ante-câmaras" (Torrado, I975: 36), como se de animais se tratassem, dado que esperar em bicha significa, muitas vezes, aguardar em pé, umas pessoas atrás das outras, horas a fio, sem condições mínimas de conforto.

Ora durante a ausência do rei, o gato Xanana deitou-se em cima do trono e, de repente, entrou na sala do trono "um velho camponês, cansado de esperar, de pé, na ante-câmara (...) de olhos postos na alcatifa da sala e torcendo as mãos, num grande acanhamento" (Torrado, I975: 37, 38). Homem humilde, pobre, com baixa instrução, este velho camponês encara o gato Xanana, sentado no trono, com estupefação. E a sua surpresa e a sua ignorância, ele que nunca tinha visto um rei, levam-no a confundir o gato Xanana com o rei:

Que intriga seria aquela? (...) Seria aquele bichano um rei disfarçado de gato? Ou um gato disfarçado de rei? E se fosse o rei um gato? Um rei gato? O rei dos gatos? Tanta confusão de perguntas sem resposta atordoava o camponês. (Torrado, I975: 38)

Esta confusão entre o gato Xanana e o rei permaneceu até ao final da suposta audiência do camponês. $\mathrm{O}$ camponês decidiu expor o seu problema e negociar com o gato Xanana, como se este fosse o rei, acabando por voltar para a sua terra e por pagar anualmente, ao rei, a renda proposta ao gato, aquando da audiência. Esta renda era um cesto cheio de peixe que o rei recebia, todos os anos, na mesma época, e que, sem saber o que lhe havia de fazer, oferecia-o ao gato. A história termina, de modo irónico, como é costume: "É justo." (Torrado, I975: 39).

E assim, neste conto curto, encontramos uma forte crítica aos poderes despóticos, em várias dimensões, como é apanágio na obra de António Torrado: critica-se o poder absoluto do rei, a falta de voz atuante das elites e a sua consequente submissão a esse poder, o afastamento entre o rei e os seus súbditos, entre as instituições e o povo, um povo mantido na pobreza e na ignorância.

O Trono do Rei Escamiro foi editado pela primeira vez em I977, na coleção Caracol, da Plátano Editora e pela segunda vez em I985, na coleção Sete Estrelas, da Livros Horizonte Editora. Mais recentemente, este texto surge editado em 20Io, pela Editora Civilização, num álbum ilustrado por Ricardo Rodrigues, que alberga uma outra narrativa, álbum este que se intitula O Trono do Rei Escamiro...E Outra História.

No texto $O$ Trono do Rei Escamiro, editado também já após a Revolução de 25 de abril de 1974, António Torrado deixa transparecer o seu pensamento político. O protagonista da curta narrativa O Trono do Rei Escamiro é o rei homónimo, metáfora do poder absoluto, centrado na figura do monarca e num trono, um dos símbolos do poder real, que exprime a glória, o domínio e a superioridade do rei sobre os seus súbditos. Ora como qualquer trono, de um modo geral, o trono do rei Escamiro "Era um trono muito 
rico, todo trabalhado" (Torrado,I977: 2) e que "era digno de ser visto" (Torrado,I977: 2), condizente com a majestade do próprio monarca. Era neste trono que o rei Escamiro recebia os seus súbditos "a corte, os ministros, os embaixadores e gente assim” (Torrado,I977: 2). Note-se que o rei Escamiro só recebe as pessoas que normalmente pululam junto do poder, sendo a expressão "gente assim" uma metáfora para denominar todo um círculo de pessoas consideradas próximas do poder e que se equiparam aquelas classes que são de facto nomeadas no texto.

Porém, este poder do rei Escamiro, como todos os poderes absolutos, começa a ser colocado em causa. Mais uma vez, o trono assume aqui um papel simbólico, já que "Mas um dia, o trono começou a balançar um bocadinho. Uma das pernas tinha dado de si” (Torrado,ı977: 4). E começa, neste episódio, o caminho para a queda do poder absoluto e para a instauração de uma democracia, protagonizada pelo povo, aqui simbolicamente representado pelo aprendiz de carpinteiro. Na verdade, parece-nos que o carpinteiro (real, neste caso) já se encontra numa categoria socialmente mais elevada, dado que, quando é chamado pelo rei, não pode comparecer, visto que está de férias, um privilégio decerto só possível para os mais bafejados no círculo do monarca. É mesmo o povo que atende ao chamado real e que vai tentar consertar o trono do rei. O arranjo do trono, progressivo e gradativo, numa tentativa de equilíbrio nunca conseguida, que termina com a ausência de pernas no assento real, parece-nos uma metáfora para o caminho a ser percorrido, pelas comunidades e pelas suas instituições, para se alcançar uma sociedade mais justa, mais livre, mais democrática. Afinal, o rei Escamiro Ramiro até achou piada ao facto de ter ficado sem trono, dando-lhe mesmo uma outra utilidade: "O rei achou graça. Achou mesmo imensa graça e mandou fazer um baloiço com o que restava do trono." (Torrado, I977: I2), utilidade que nos remete para o mundo da infância e para a esperança num mundo mais justo e melhor que as crianças representam.

A coletânea Dez Contos de Reis, da qual iremos abordar dois textos ("O elefante do rei" e "O rei das pernas tortas") foi publicada em I99o. Mais uma vez, nestes textos, é explícito através do insólito, do humor e do nonsense, o pensamento político de António Torrado.

Comecemos por "O elefante do rei". O elefante branco do rei era a montada principal de um monarca, absoluto certamente, dado que tudo naquele elefante era propriedade sua "A tromba era do rei. As orelhas eram do rei. As patas eram do rei. $\mathrm{O}$ áspero dorso (...) era do rei." (Torrado, I990: II). A caracterização deste elefante branco, expressa através de múltipla adjetivação, remete-nos para qualidades que decerto são facilmente transpostas para as figuras reais - o elefante era "Sólido e sisudo. Majestoso." (Torrado, I990: II). Porém, este elefante tinha, seguramente, um dos atributos mais apreciados pelos reis - ele era "Obediente" e tudo na vida dele girava em função do monarca "Obedecia-lhe. Pertencia-lhe. A vida dele era a vontade do rei." (Torrado, I990: II).

Esta submissão total ao soberano era apenas abalada, de forma leve mas insistente, pela pertença do seu filho, "um pequeno elefante branco" "de dorso macio e passos hesitantes" (Torrado, I990: II), ao rei. E é através do filho e por causa do filho que o 
elefante branco se atreve apenas a duvidar, dúvidas estas quase esquecidas quando o pequeno elefante branco se torna a montada do pequeno príncipe. Num processo rápido e gradativo assistimos a uma mudança de comportamento no elefante branco, numa metáfora, parece-nos, do que acontece em muitos processos políticos - a interrogação vai-se instalando paulatinamente e um acontecimento pode, de forma célere e progressiva, dar origem a uma transformação profunda. Ora a ténue, mas persistente hesitação do elefante branco, em relação à propriedade do seu filho, toma enorme proporções e converte-se em questionamento quando o rei manda matar o pequeno elefante branco,

- Elefante que deixa cair um descendente real é elefante a abater. Matem-no.

O grande elefante estremeceu. Então o filho não lhe pertencia? O rei podia assim tanto? Por ter caído o filho do rei, que quase nada se magoara, morria o filho do elefante? Isso era justo? (Torrado, I990: I3).

E o questionamento passa rapidamente a revolta, quando se aproximam "os soldados com as lanças" (Torrado, I990: I3), quando o pequeno elefante olha desorientado para o pai. É neste momento que se dá a amotinação. De seguidor quase cego, o elefante branco passa a líder, fugindo para a floresta com o seu filho, e sendo seguido por todos os elefantes do séquito, ganhando assim a sua liberdade. Já o rei, acaba por "regressar ao palácio a pé” (Torrado, I990: I3), numa mensagem irónica, cómica e subtil que nos aponta para a importância da crítica, da reflexão, da interrogação para a construção de sociedades mais justas e equilibradas, onde os cidadãos são “donos deles próprios” (Torrado, I990: I3).

Em "O rei das pernas tortas" deparamo-nos com um rei, mais uma vez absoluto, que "comandava a torto e a direito" (Torrado, r990: 29) e que tinha uma particularidade física - tinha as pernas tortas. O seu poder discricionário, desde criança, fez com que todas as pessoas que se relacionavam com ele, ao longo da vida, tivessem que "arquear o mais possível as pernas" (Torrado, I990: 29).

O ridículo e o humor tão característicos na escrita de António Torrado, muitas vezes ao serviço do seu pensamento político, estão bem presentes nesta narrativa. Para além de satirizar o monarca, são hilariantes os episódios do exército das pernas tortas ou dos embaixadores dos países vizinhos, que "Mostrarem-se com as pernas direitas, nunca! A mínima desatenção à etiqueta desencadearia cortes de relações entre países ou sabe-se lá que mais..." (Torrado, I99O: 29). De novo, a tirania deste poder absoluto é posta em causa por um facto repentino, drástico, que leva os súbditos a perderem o medo, a libertarem-se, a dizerem o que pensam, originando uma transformação na forma de governar.

Ora certo dia, o fogo, "sem pedir licença" (Torrado, I990: 30), invade o palácio. Curioso é o fogo começar nas cozinhas. Se aqui pode realmente começar um fogo pela natureza do que é uma cozinha, simbolicamente é muito pertinente que o incêndio tenha ateado neste compartimento. Locais pouco nobres, servidos por gente do povo, este fogo 
na cozinha personifica também a revolta que muitas vezes se inicia junto das populações mais pobres e mais desfavorecidas, vítimas maiores dos desmandos de poderes autocráticos, fogo este que como um rastilho acaba por chegar aos "salões do palácio" (Torrado, I990: 30 ).

No fragor da revolta, na aflição do fogo, as pessoas assumem aquilo que verdadeiramente são, deixando para trás os opressores à mercê dos acontecimentos, como este rei que "No meio daquela confusão deixou cair a coroa, partiu o ceptro e ficou com o manto todo chamuscado." (Torrado, ı990: 30), ouvindo um criado, que não o reconheceu, dizer-lhe "Deixe-se de tolices, amigo! Nesta aflição cada um corre com as suas próprias pernas e não com as do rei." (Torrado, I990: 30). E, no desfecho desta narrativa, estas são as palavras que o rei profere, na inauguração do novo palácio, de uma outra era, marcada pela liberdade.

\section{Conclusões}

Ao longo deste estudo, centrámo-nos nalguns textos de literatura infantil do escritor português António Torrado, onde se plasma bem o seu pensamento político e ideológico. É de assinalar que alguns dos seus textos mais antigos foram redigidos na época da Revolução de 25 de abril de I974, um período bastante conturbado para o país, onde a democracia ainda não estava consolidada. Aliás Blockeel (2OOI) assinala que a evolução e a renovação na literatura infantil portuguesa, registada após a Revolução dos Cravos, tardaram ainda cerca de cinco anos. Segundo esta autora, os primeiros anos a seguir à Revolução foram tempos caóticos, que se refletiram também nas narrativas para crianças, as quais possuíam um valor literário reduzido, visto que as preocupações eram mais de teor ideológico. Assim, a maioria destas narrativas desapareceu do mercado editorial atualmente.

Estes factos mostram a importância das obras de António Torrado na literatura infantil, não só pelas reedições dos seus textos, mas também pela mensagem que as obras do autor veiculam para os leitores mais novos.

Nas obras assinadas por António Torrado encontramos, de uma forma metafórica, o apelo à liberdade e a condenação da opressão. Há, na sua obra, sempre uma mensagem de esperança, uma vez que os tiranos acabam por ser depostos, permitindo o início da construção de uma sociedade mais igualitária e mais democrática.

Neste ensaio ficou bem patente a persistência em dar a conhecer a perseguição e a opressão de que são alvos os que, pelo seu modo de agir ou simplesmente de estar, não se ajustam a visões unidimensionais da realidade humana.

Assim, estes textos, quando lidos e analisados, em sala de aula, à luz de princípios metodológicos como os de uma literacia crítica (Comber, I998; Ciardiello, 2004; Bourke, 2008; Hall e Piazza, 20o8; Soares e Wood, 2OIO), podem contribuir para formar crianças livres, capazes de interrogar as práticas e serem sujeitos promotores da justiça 
social. Estas obras oferecem visões críticas e alternativas do mundo suscetíveis de responderem às questões endereçadas pelas crianças, "Porquê?", "Porque é que as coisas são deste modo?", "Por que razão as situações não podem ser diferentes?". Cabe-nos a nós, mediadores de leitura, através da literatura infantil ajudá-las a encontrar o seu caminho de cidadania. 


\section{Referèncias}

- Balça, A., Azevedo, F. \& Selfa, M. (20I7). Literatura infantil portuguesa en tiempos de la Dictadura: censura y voces de resistencia. Ocnos. Revista de Estudios sobre Lectura, I, IO7I2O.

Obtido em 29 de maio de 2018 desde https://www.revista.uclm.es/index.php/ocnos/article/view/ocnos_20I7.I6.I.II6o/pdf

- Blockeel, F. (2OOI). Literatura juvenil portuguesa contemporânea: identidade e alteridade. Lisboa: Caminho.

- Bourke, R. T. (2008). First Graders and Fairy Tales: One Teacher's Action Research of Critical Literacy. The Reading Teacher, 4, 304-312.

- Ciardiello, A. V. (2004). Democracy’s Young Heroes: An Instructional Model of Critical Literacy Practices. The Reading Teacher, 2, I38-I47.

- Comber, B. (I998). Critical literacy: What's it all about? Learning Matters, 3, 8-13.

- Hall, L. A. \& Piazza, S. V. (20o8). Critically Reading Texts: What Students Do and How Teachers Can Help. The Reading Teacher, 4, 32-4I.

- Hollindale, P. (I988). Ideology and the Children’s Book. Signal, 55, II-30.

- Pimenta, R. (20IO, Setembro 9). António Torrado: "Já escrevi sobre tudo e mais alguma coisa”. Público, s/p. Obtido em 28 de maio de 2018 desde https://www.publico. $\mathrm{pt} / 2 \mathrm{OIO} / \mathrm{og} / 2 \mathrm{I} /$ culturaipsilon/noticia/antonio-torrado-ja-escrevi-sobre-tudo-e-mais-alguma-coisa-I $457^{\mathrm{O}} 7^{2}$

- Reynolds, K. (2007). Radical Children's Literature: Future Visions and Aesthetic Transformations in Juvenile Fiction. New York: Palgrave MacMillan

- Soares, L. B. \& Wood, K. (2OIO). A Critical Literacy Perspective for Teaching and Learning Social Studies. The Reading Teacher, 6, 486-494.

- Steiner, G. \& Antunes, A. L. (2OII). O dia do encontro. Cambridge, og October. Ler. Livros \& Leitores, $2,34^{-5}{ }^{2}$.

- Sutherland, R. D. (1985). Hidden Persuaders: Political Ideologies in Literature for Children. Children's Literature in Education, 3, I43-I57.

- Todorov, T. (197I). As categorias da narrativa literária. In AA.VV. (Org.) Análise estrutural da narrativa (pp. 209-254). Petrópolis: Vozes Editora. 
- Torrado, A. (1972). O Veado Florido. Lisboa: Editorial O Século

- Torrado, A. (i975). O gato que era rei. In A. Torrado (Org). O jardim zoológico em casa (pp. 34-36). Lisboa: Plátano Editora

- Torrado, A. (i977). O Trono do Rei Escamiro. Lisboa: Plátano Editora.

- Torrado, A. (1990). O elefante do rei. In A. Torrado (Org). Dez Contos de Reis (pp. II-I3). Lisboa: Edições O Jornal.

- Torrado, A. (I990). O rei das pernas tortas. In A. Torrado (Org). Dez Contos de Reis (pp. 29-30). Lisboa: Edições O Jornal. 